\title{
Commentary: Can a fracture be a good thing, and when?
}

\author{
George L. Hicks, MD
}

\author{
From the Program of Cardiothoracic Surgery, University of Rochester Medical Center, Rochester, NY. \\ Disclosures: Author has nothing to disclose with regard to commercial support. \\ Received for publication Jan 23, 2019; accepted for publication Jan 23, 2019; available ahead of print March 7 , \\ 2019. \\ Address for reprints: George L. Hicks, MD, University of Rochester Medical Center, 601 Elmwood Ave, Roches- \\ ter, NY 14642 (E-mail: george_hicks@urmc.rochester.edu). \\ J Thorac Cardiovasc Surg 2019;158:1329-30 \\ $0022-5223 / \$ 36.00$ \\ Copyright (c) 2019 by The American Association for Thoracic Surgery \\ https://doi.org/10.1016/j.jtcvs.2019.01.089
}

In most aspects of medicine and life, we have grown to believe that fractures are not beneficial. Fractures of the liver, spleen, bones, and even relationships have always carried an ominous connotation. In this month's Journal, however, the article by Allen and colleagues," "Bioprosthetic Valve Fracture: Technical Insights from a Multicenter Study," provides cogent data for the use of bioprosthetic valve fracture (BVF) in valve-in-valve (VIV) procedures to optimize postimplantation transcatheter valve gradients.

The article by Allen and colleagues ${ }^{1}$ is a multiinstitutional review of 75 patients undergoing VIVtranscatheter aortic valve replacement (TAVR) procedures during which the balloon valve fracturing technique was used for small existing bioprosthetic valves (average $21.5 \mathrm{~mm}$ ). The surgeons involved used both balloonexpandable or self-expanding balloons and analyzed their results according to the timing of the balloon intervention (either before or after VIV-TAVR). There were no aortic root disruptions, coronary occlusions, or new pacemakers, and in-hospital or 30-day mortality was $2.6 \%$ (2/75). Final mean transvalvular gradient was $9.2 \pm 6.3 \mathrm{~mm} \mathrm{Hg}$, but it was significantly lower when BVF was performed after VIV-TAVR than after BVF was performed first $(8.1 \pm 4.8 \mathrm{~mm} \mathrm{Hg}$ vs $16.9 \pm 10.1 \mathrm{~mm} \mathrm{Hg} ; P<.001)$. After a multivariant analysis, Allen and colleagues ${ }^{1}$ concluded that performing BVF after VIV-TAVR $(P<.0001)$ and using a larger BVF balloon $(P=.013)$ were the only independent predictors of lower final mean gradient.

In the article, Allen and colleagues, ${ }^{1}$ provide important details about balloon sizing, measurement of the existing bioprosthetic valve internal diameters, and the objective determination of successful fracture of a bioprosthetic valve; that is, a sudden drop in the inflation pressure of the inflation-deflation device and balloon-waist release, as illustrated in the central picture of the article. Allen and colleagues ${ }^{1}$ further caution practitioners about patient selection, citing patients with low-lying coronaries, chimney aortic roots, and narrow sinuses as possibly poor candidates, as well as suggesting avoidance of BVF in heavily calcified

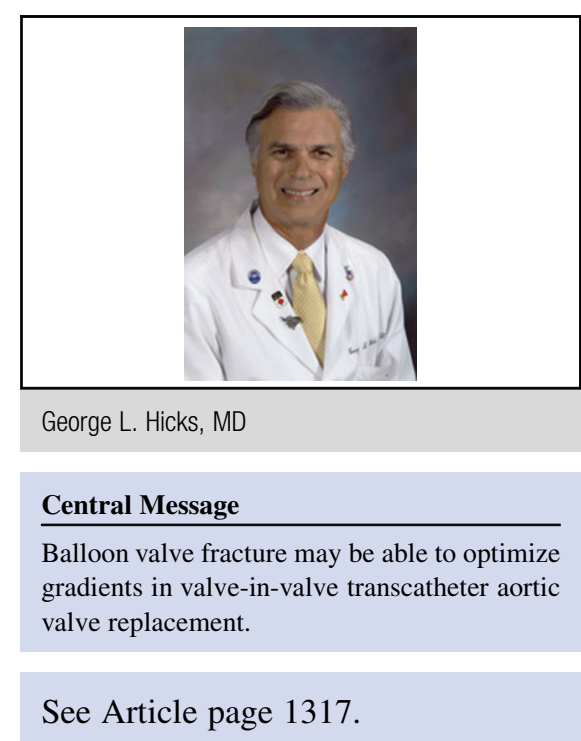

roots and surgical valves implanted in the intra-annular rather than supra-annular position.

Although a multicenter collaboration, the study is limited by relatively small numbers spread over several institutions, but Allen and colleagues ${ }^{1}$ have provided valuable information about a procedure which undoubtedly will continue to increase in frequency. The article demonstrates that goals of procedural safety and low gradients can be possible in VIV, and now the long-term results of high-pressure trauma to an existing VIV-TAVR remain to be proved. The study remains inconclusive with regard to the timing or use of BVF, because the choice of which of the 2 types of balloons used was left up to the individual surgeons, and the study is numerically weighted heavily in favor of BVF after implantation ( $88 \%$ vs $12 \%$ ). Likewise, the criteria to perform BVF remain unclear, with postimplant (pre-BVF) gradients of $20 \mathrm{~mm} \mathrm{Hg}$ remaining a gray area requiring larger numbers and follow-up to accurately determine whether BVF or nonintervention is best. Allen and colleagues ${ }^{1}$ do, however, provide convincing hemodynamic data comparing baseline and the postdilation impact that BVF had on reducing the residual gradients after VIV-TAVR. Finally, high-pressure BVF dilatation is not without risk, and 2 acute transcatheter valve injuries $(2.7 \%)$ were documented. One patient had a Sapien S3 valve (Edwards Lifesciences, Irvine, Calif) and the other had an Evolut $\mathrm{R}$ valve (Medtronic Inc, Minneapolis, Minn), with the etiology of the damage unclear in both cases. 
Success in BVF and VIV thus depends on patient selection, possible timing of the BVF, and expertise regarding which valves can and cannot be fractured. Allen and colleagues ${ }^{1}$ begin the examination of this relatively new technique by providing some ground rules and important observational data, but they acknowledge that there is much to learn about optimizing long-term gradients with the BVF-VIV procedure. We thus are left to understand that fractures can be beneficial, but the questions of exactly when, with what balloons, and with what valves remain for larger, controlled studies to provide answers for our patients in the future.

\section{Reference}

1. Allen KB, Chhatriwalla AK, Saxon JT, Cohen DJ, Nguyen TC, Webb J, et al. Bioprosthetic valve fracture: technical insights from a multicenter study. J Thorac Cardiovasc Surg. 2019;158:1317-28.e1. 